\title{
SUSTAINABILITY DEVELOPMENT INDEX (SDI) FOR HIGHRISE BUILDINGS WITH CONCEPT OF FIGURE OF MERIT
}

\author{
Ajit Sabnis ${ }^{1}$, M R Pranesh ${ }^{2}$ \\ ${ }^{1}$ Department of Civil Engineering, School of Engineering and Technology, \\ Jain University, Bangalore, India \\ ${ }^{2}$ Professor, Department of Civil Engineering, School of Engineering and Technology, \\ Jain University, Bangalore, India
}

\begin{abstract}
Urbanisation is demanding for construction of high-rise buildings. Different materials are the essential components of construction. Energy is the basic requirement during the life cycle of a building. High-rise buildings are energy intensive. Impact of embodied energy in high-rise buildings is assessed through the concept of 'Figure of Merit' (FoM), an exclusive nondimensional parameter. FOM parameter represented as $Z_{C}$ accounts for two important engineering properties namely Modulus of Elasticity and Density of materials used in the construction process along with unit cost of material and cost of construction per unit area. This FoM equation is further integrated with other energy indicators including embodied energy, embodied carbon (CO2e), transport energy and other derived coefficients to give rise to a set of dimensionless interaction values designated as II, I2 and I3. The complex interaction phenomena between the Construction Materials, Embodied Energy footprint and Global warming (CO2e) are simplified as: I1-Construction Materials and Embodied Energy interaction; I2- Embodied Energy and Global Warming Interaction; I3- Global warming and Construction materials Interaction. Three interaction phenomena results in the net outcome of Sustainability Development Index (SDI) enabling use of FoM as a tool in assessing the energy impact of construction materials on natural environment in the pre-construction and construction phases of building's life cycle. The aim of this paper is to formulate a Sustainability Development Index which can be applied to assess the levels of sustainability of materials. SDI is expressed in terms of percentage of sustainability. SDI model has been developed based on three interaction factors. A case with SDI model has also been presented for formwork system.
\end{abstract}

Keywords: Embodied Energy, Embodied Carbon, High-rise buildings, Environmental Impact, Figure of Merit, Energy Efficiency, Global Warming, Sustainability Development Index, Construction Materials.

\section{INTRODUCTION}

Sustainable development and the impact of buildings on natural environment result in high rise buildings attain greater importance in urban habitat all over the world in general and more so in developing countries like India. Demographic extrapolations indicate that by 2050, urban areas will have about $70 \%$ of the total population and according to 2011 Indian census, out of India's total population of 1.21 billion, $31.5 \%$ people live in urban areas and this number will reach $50 \%$ by 2030 . It is expected that between 2015 and 2030, pace of urbanization will be at the rate of $2.1 \%$, almost double than that of China's growth rate. As cited by JLL, strategic consulting, Economic survey 2015-16 of India report shows, a shortage of about 20 million homes in India. In urban environment, the report says, 'Economically Weaker Sections-EWS' and 'Lower Income Groups-LIG' together account for $95 \%$ of the urban housing shortage in the country. Migration to urban areas from rural habitat will create pressure on the available land mass and results in the increase of land prices coupled with the decrease in availability of large spaces for large constructions.
In India, migration studies show that the urbanization pattern is restricted only to a few cities where high rise buildings are built. High rise buildings can yield large floor areas on small pieces of land. Optimum utilization of land, energy and natural resources then become governing factors for high rise buildings. With the advanced designconstruction technologies available and the demand for real estate soaring, high rise buildings appear to provide a better solution in terms of living conditions at affordable pricing.

Super tall and mega tall buildings are also being constructed in many countries which are not part of this investigation. As observed by Adrian Smith [1], construction cost of such super tall and mega tall structures are significantly high as compared to other high rise buildings and the efforts to build these structures are enormous. Super and mega tall buildings many a times become status symbols of a country and substantially influence the areas around. Under these circumstances, energy efficiency measures have little role to play. 


\subsection{TALL BUILDINGS AND SUSTAINABILITY}

From sustainability point, tall buildings are high energy intensive and have different footprints as compared to low rise buildings. The environmental impact of tall buildings on the cityscape is due to involvement of expensive construction methodologies, large quantum of construction materials, mechanical ventilation, vertical transportation, artificial lighting, excess heat gain due to outer skin glazing in hot climatic zones, heat island effect, shadow effect on micro climate, cluster effect and Heat, Ventilation and Air conditioning (HVAC). These issues are to be addressed in addition to the various structural loads and structural systems keeping conservation and sustainability as principal criteria.

World Commission and Environmental Development (WCED) report, 1987, suggests that designing a sustainable environment should not only cater for the needs of the present but also take resources required by future generations. This can be achieved by exercising judicious control over the use of available natural resources, utilizing low energy materials, applying energy efficient construction methodologies and technologies, using maximum renewable energy, implementing eco-friendly design strategies. Such steps incorporated help in substantially reducing energy consumption during all four phases of building's life cycle. Application of building automation processes which help in reducing energy consumption in use phase of buildings also to be taken into account at the designing stage.

'Tall Buildings and Sustainability Report' [2] by Greater London Authority (GLA), 2002, mentions that sustainable development has to meet four objectives simultaneously. They are: Societal progress recognizing the needs of all, Judicious use of natural resources, Stable economic growth and Environmental protection.

\subsection{Tall Building Definition}

Figure 1 shows comparative heights of world's tallest buildings.

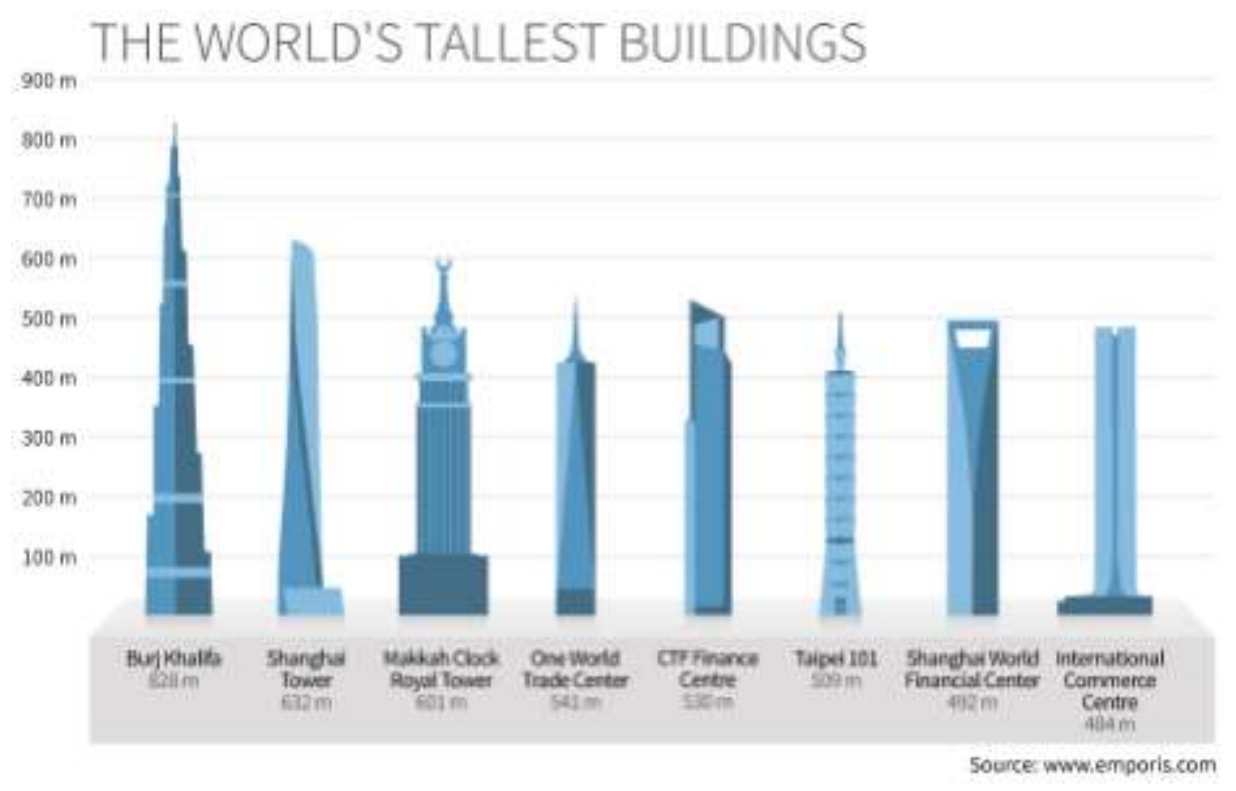

Figure 1: Comparative heights of world's tallest buildings

There is no one internationally acceptable definition of what constitutes a tall building. Council on Tall Buildings and Urban Habitat (CTBUH) observes, for a building to be designated as tall, it should display an element of tallness with reference to relative height, proportion and technologies adopted. Though, the number of floors is an inadequate indicator in designating a building as tall, 14 floors and above or height of a building more 50 meters or more can be termed as tall. While buildings 300 meters and above are termed as super tall, 600 meters and above are termed as mega tall.

Emporis standards committee classifies buildings between 35 meters and 100 meters as high rise and buildings over and above 100 meters high as skyscrapers.

There have been several attempts to classify tall buildings even from Fire Safety point of view, which appears to be logical in present days. As observed by Konke M E, ASIS International 2006, any building beyond the reach of firefighting equipment is a high-rise structure, approximately restricting it to about ten floors high.

National Building Code (NBC) of India, 2015, restricts maximum height of buildings above the ground level in relation to the width of a street in front of the building, floor area ratio and the local fire-fighting stipulations. These are specified and tabulated in part 3 of National Building Code of India.

In this paper, unless otherwise mentioned, height criteria considered are as shown in Table 1. Based on the various definitions, in this paper, high-rise buildings are defined as those buildings which are 100 meters higher. 


\begin{tabular}{|c|c|c|c|}
\hline \multicolumn{4}{|c|}{ TABLE 1- TALL BUILDINGS HEIGHT CRITERIA } \\
\hline CATEGORY & HEIGHT & UNIT & CRITERIA \\
\hline Mega Tall & $>600$ & meters & CTBUH \\
\hline Super Tall & $300-599$ & meters & CTBUH \\
\hline Skyscraper & $>100$ & meters & Emporis \\
\hline High-Rise & $35-100$ & meters & Emporis \\
\hline
\end{tabular}

\subsection{INDIAN SCENARIO}

According to CTBUH published list in 2016, India has registered about 130 tall buildings ranging from 13 to 60 floors, use ranging from residential to office to institutional. Out of these 130 buildings, 2 are 250+ meters; 32 are 150 to 250 meters; 49 are 100 to 150 meters and 20 are between 60 and 100 meters. Majority of these buildings are located in Mumbai. From the data available from CTBUH published list, about $98 \%$ of the buildings use concrete as the main structural material for construction.

Assuming the same trend continues in India and buildings below 150 meters utilize concrete as main structural material, buildings below 150 meters are considered in the present discussion.

As noted by Jukka Heinonen et al [4], majority studies till now have laid stress on energy consumption during the operative-maintenance phase of a building and this has resulted in several energy efficient measures to contain GHG emissions. However, studies carried out by Blengini et al.[23], Saynajoki et al.[5] suggest more emphasis be placed to quantify the energy impact and related emissions due to construction materials during the preconstruction and construction phases of a building. Emissions during construction phase appear in a short time period and are more harmful in comparison to the emissions that occur during the operational phase, which are distributed over a long period. It is also imperative that improvements implemented to reduce energy consumption during the use phase, enhances the relative importance of embodied emissions in the early stages of life cycle of a building.

Jingke hong et al [6] with their case study referred to buildings in China have reiterated that construction industry plays a vital role in contributing to global greenhouse gas (GHG) emissions and that it plays a significant role in contributing to global warming.

According to the report generated by Intergovernmental Panel on Climate Change (IPCC) 2001, 40\% of the global energy consumption is by the building sector contributing to about $25 \%$ of global carbon dioxide emissions. The report also observes, global $\mathrm{CO}_{2}$ emissions generated from buildings increased at an average of $2.7 \%$ per year from 1999 to 2004 (Metz et al., 2007).

Due to complexities involved in construction phase which includes material extraction, processing, manufacturing, transportation and implementation in construction, accurate assessment of energy impact on natural environment becomes difficult and hence there is need to develop an integrated assessment tool which enables to quantify sustainability levels during the design stage. This assessment will suggest use of alternative sustainable materials helping $\mathrm{CO}_{2}$ mitigation.

Ignacio et al [7] with their study on 60 buildings spread across 9 countries observed that more than $50 \%$ of the total embodied energy in a building is due to materials constituting the frame of a building. In view of this, use of alternative materials with low embodied energy and high recyclability content are recommended to reduce the overall embodied energy in a building. For instance, the use of recycled steel and aluminum imparts savings to the extent of more than $50 \%$ in embodied energy.

Several researchers have studied the energy impact of built environment due to construction materials and processes in developing nations. BVV Reddy and K S Jagadish [19] stresses upon the need of using alternative construction technologies such as Stabilised mud Blocks, prefabricated roofs, masonry vaults, etc. to reduce energy impacts. BVV Reddy and KS Jagadish carried out energy evaluation of three independent buildings based on actual materials consumption excluding the energy content of doors and windows. They found energy consumed by a multi-story building was of the order $4.2 \mathrm{GJ} / \mathrm{m}$ as compared to a two story building with bricks as load bearing walls was found to be $2.9 \mathrm{GJ} / \mathrm{m}^{2}$.

\subsection{HIGH-RISE CLASSIFICATION BASED ON UTILITY}

In developing nations like India, high rise buildings are essentially divided in two categories namely Residential and Commercial. Mixed use buildings are minimal in numbers. Majority residential buildings including low-rise and highrise have their outer envelopes built using concrete blocks with percentage of window openings as per codal provisions. In case of commercial buildings, the envelope of a building is essentially glazed.

Adrian Smith [1], in his article, "Tall, Global and Sustainable" suggests harvesting of renewable energy to mitigate the adverse impact of GHG emissions and adopting efficient systems to reduce the waste. The study also suggests, three-to-four-story buildings perform best due to simple methodologies involved in construction and maintenance. Adrain further emphasizes the need for striking balance between building tall and spreading horizontal to meet the needs of growing population.

\subsection{ROLE OF EMBODIED ENERGY (EE)}

Cradle to cradle assessment approach includes energy analysis through all phases of life cycle of a building from material extraction to the end of life stage of a building. Thus, total life cycle energy in a building includes embodied energy, transport energy, operation energy and demolition energy. Total embodied energy is further categorized into direct and indirect energy. Direct energy constitutes energy 
consumed during various processes such as, on site construction, erecting temporary structures such as formwork, prefabrication, assembly of components, transportation within the construction premises and actual energy utilized for managing the construction site. Indirect energy includes initial embodied energy and recurrent embodied energy. Initial embodied energy is the energy consumed from raw material extraction stage till the product is delivered to site. Recurrent energy is the energy consumed during various maintenance and refurbishing processes. Demolition energy includes energy consumed in demolition and transport of demolished materials

Manish et al [8], in their review observe the importance given to operational energy of a building as compared to embodied energy which occurs in the initial stages of building's life cycle. However, recent studies have shown that embodied energy also plays significant role in the total life cycle energy. This is in agreement with the studies made by Jukka Heinonen et al [4], Blengini et al.[23], Saynajoki et al.[5]

Advanced construction technologies and methodologies have further resulted in the increased significance of embodied energy and the reasons can be attributed to:

- Modern buildings have comparatively larger areas of construction and calls for higher quantum of materials.

- Modern construction methodologies require increased levels of construction mechanization due to shortage of skilled manpower.

- Large number of options available as construction materials for various utilities which are cost and energy intensive.

- Increased use of high energy intensive materials like steel, glass, stainless steel and sophisticated envelope materials.

- Increased distances causing extra fuel consumption during transportation of materials.

There is a general perception that tall buildings are not sustainable due to large amount of materials they consume and expensive construction methodologies required to be adopted including specialized formwork systems. In addition, tall buildings are required to resist wind loads while their low rise counterparts are not designed to cater for wind loads. Further, Paolo Foraboschi et al [9] observe, the need of gravity load resisting design with heavier components especially in the lower parts of a tall structure. Further, the research conducted by Paolo Foraboschi et al [9], confirms the use of embodied energy as a suitable tool to to be considered in designing tall buildings with sustainable criteria.

Current embodied energy assessments are based on energy inventories which in turn are based on the data available at the upstream end which by themselves may be reliable or unreliable. In addition, these data are country specific. Applicability of these energy inventories to all geographic locations having different climatic conditions without suitable modifications may give rise to error in energy evaluations.

As observed by Dixit et al [10], energy intensities of several materials along with their carbon intensities are published by Hammond and Jones [11] of University of Bath, United Kingdom. Energy intensities proposed by Hammond and Jones do not include the transport energy from factory to site but includes all energy consumption from raw material extraction stage till the product is manufactured and kept ready for dispatch from factory. In version V2.0, embodied energy and carbon coefficients have been updated and majority carbon data is converted into $\mathrm{CO}_{2}$ equivalent.

Recent studies conducted by Alcorn and Baird [12] utilizes hybrid analysis while arriving at updated energy intensity coefficients applicable to New Zealand to avoid inaccuracies and limitations embedded in energy values. Buchanan and Honey [13] uses energy coefficients suggested by Baird and Chan (1983), while investigating the total amount of energy required constructing a building and the impact due to carbon dioxide emission. Significant contributions in assessing the impact of embodied energy and carbon emissions are made by several researchers including Adalberth [14] [15], Pullen [16], Crawford and Treloar [17] and Lenzen et al. [18].

Inventory coefficients that are available have their own limitations. While assessing the impact using these values various forms of energies consumed during transportation to site, efficiency of the manufacturing processes, fuel efficiency of transport vehicles, climatic conditions, energy tariffs are to be considered. As these parameters vary from place to place, values beyond cradle to gate boundary becomes difficult. Studies show the absence of standard methodology enabling assessment of sustainability level in a building and calls for the development of an integrated solution.

As observed by B.V Reddy [19], variation in embodied energy in buildings is dependent on the choice of construction materials and construction methodologies adopted. Hence there is a need to consider the range of embodied energy coefficients while assessing the environmental impact using EE as a tool. This claim is in consistent with the range of values published by Michael Ashby [20] under Material profiles. The author also observes that the reason for not having precise values is due to lack of sophisticated test-machines to measure embodied energies and carbon footprints.

\subsection{DEVELOPMENT OF SUSTAINABILITY INDEX (SDI)}

Sustainability Development Index (SDI) is an indicator derived using Figure of Merit as a tool to perform many functions and help in effectively rating the sustainability level of a building or any other infrastructure project prior to commencement of construction. SDI considers ten primary parameters which are mainly responsible in understanding 
the energy efficiency of a construction project. SDI will help in assessment of sustainability level in design phase of a building and thus gives an option to reduce the energy, emission impact during preconstruction phase and can be applied to any building or infrastructure project.

In the context of existing limitations and variations in using embodied energy as a tool in assessing the energy impact of built environment on natural environment that cannot be applied to all buildings in all climatic conditions, there is a need to develop a new sustainability index based on standard engineering properties of materials that fall within a specific range.

In this direction, the call given by the United Nations at the Conference held in Rio de Janeiro in 1992, on Environment and Development, becomes noteworthy. The United Nation's sustainable development commission calls for evolving sustainability development indicators by each country that assist and improve decision making at all levels. (UNCED, 1992; Agenda 21, Chapter 40)

Adrian et al [21] presented a methodology of designing a sustainability development index and applied it to a region in Mexico comprising seven municipalities. The outlined sustainability development index if applied to different regions, sustainability development can be assessed and compared. This comparison will help improving decision making towards sustainable development. The SDI designed by Adrian et al was expressed in terms of Figure of Merit (FoM). The SDI developed and expressed in terms of Figure of Merit by Adrian and others took into account the eco factors of a region along with socio economic aspects of human population in a region under consideration. The outcome of results constituted important findings in respect of sustainable balance between ecological order and human settlements in a region. Further, the results would assist the policy makers in arriving at decisions favouring sustainability.

Tall buildings have different footprint as compared to other low or medium height buildings with reference to aesthetic and design features, wind resistance, façade design, constructability, formwork system and their impact on surrounding areas. In 2012, Binh K Nguyen et al. [22] observed lack of detailed assessment criteria for tall buildings in respect of techniques, methodologies, services and other processes involved in construction. A design tool, Tall-Building Projects Sustainability Indicator (TPSI) for buildings above 60 meters or equivalent to about 20 floors was developed by the authors. Threshold limit of 60 meters or 20 floors was in agreement with the limits set by Fazlur Khan, 1969, while classifying tall buildings with reference to various structural systems. Figure 2 shows Classification of Tall Building Structures by Fuzlur Khan.

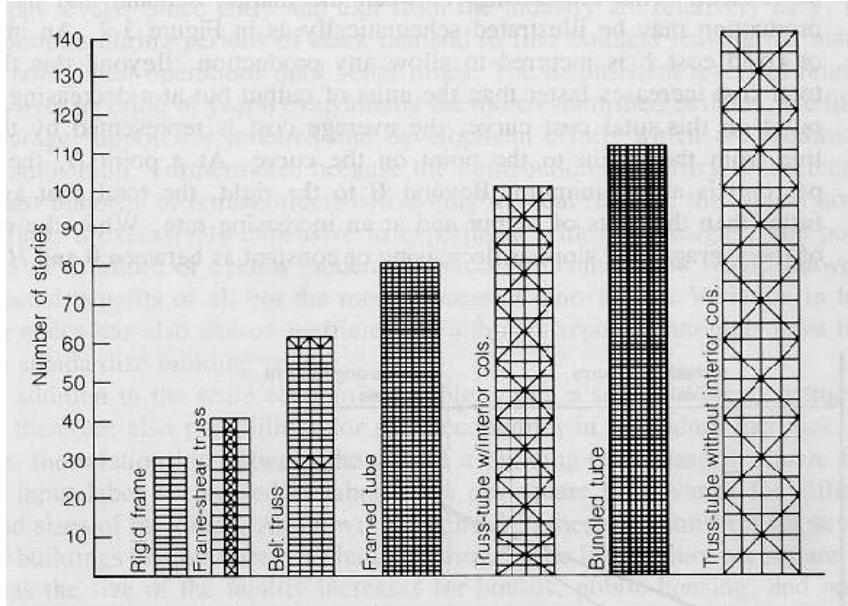

Figure 2: Classification of Tall Building Structures by Fuzlur Khan

\subsection{ASSESSMENT OF ENERGY IMPACT USING FIGURE OF MERIT (FoM) AS A TOOL}

This Presentation focuses on assessment of energy impact in high-rise buildings through the concept of 'Figure of Merit' (FOM), an exclusive non-dimensional parameter. FOM parameter represented as $Z_{C}$ accounts for two important engineering properties namely Modulus of Elasticity and Density of materials used while constructing a building along with the unit cost of a material and the cost of construction per unit area. This equation is further integrated with other energy indicators including embodied energy, embodied carbon, transport energy and other derived coefficients to give rise to a set of dimensionless interaction values. The complex interaction phenomena between the Construction Materials, Embodied Energy footprint and Global warming $\left(\mathrm{CO}_{2} \mathrm{e}\right)$ are shown in Figure 3 and simplified as:

- I1: Construction Materials-Embodied Energy interaction.

- I2: Embodied Energy - Global Warming Interaction.

- I3: Global warming - Construction materials Interaction.

I1, I2 and I3 are dimensionless interaction factors.

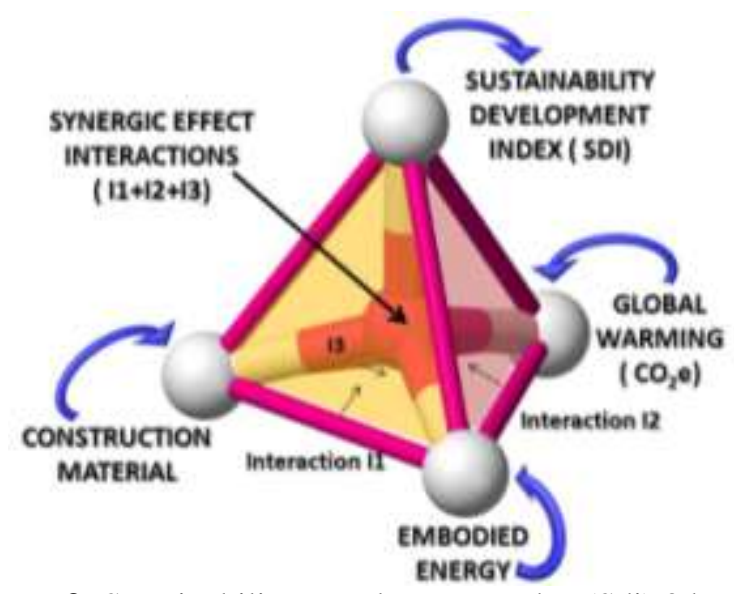

Figure 3: Sustainability Development Index (Sdi) 3d Model Image Source of Tetrahedron Model: Wikipedia 
The above three complex interaction values result in the net outcome of Sustainability Development Index (SDI) enabling use of FoM as a tool in assessing the impact of construction materials on natural environment in the preconstruction and construction phases of building's life cycle. The aim of this paper is to formulate a new Sustainability Development Index based on FoM concept and applied to evaluate sustainability levels in a building or infrastructure project. SDI developed is expressed in terms sustainability percentage.

\subsection{EQUATION OF FOM}

Figure of Merit (FoM), adopted here is a non-dimensional numerical parameter used to characterise the performance and effectiveness of a material. The FoM equation described below considers two important engineering properties of materials namely modulus of elasticity and density. FoM for various materials are derived using the following equation:

$\mathrm{Z}_{\mathrm{C}}=\mathrm{E} / \rho \times \mathrm{C}_{\mathrm{m}} \times 1 / \mathrm{C}_{\mathrm{a}}$ Equation 1

Where;

$\mathrm{E}=$ Modulus of Elasticity in $\mathrm{Kg} / \mathrm{m} 2$

$\rho=$ Density of material in $\mathrm{Kg} / \mathrm{m} 3$

$\mathrm{C}_{\mathrm{m}}=$ Cost of material in INR/m3

$\mathrm{C}_{\mathrm{a}}=$ Cost of construction per square meter in INR

Using Equation 1 above, as an illustration, values of FoM for some of the important construction materials applicable under Indian conditions were calculated taking range of Evalues from standard data tables, prevailing unit cost of construction materials and cost of construction per unit area. These are tabulated and given in Table 2.

Table 2: Figure of Merit $\left(\mathrm{Z}_{\mathrm{C}}\right)$ Values

\begin{tabular}{|r|l|r|r|}
\hline \multicolumn{3}{|c|}{ Figure nof Merit $\left(Z_{C}\right)$ Values } \\
\hline \multirow{2}{*}{ DESCRIPTION } & \multicolumn{2}{c|}{$Z_{C}$ FoM } \\
\cline { 2 - 4 } & & LOW & \multicolumn{1}{c|}{ HIGH } \\
\hline 1 & Reinforced Concrete & 0.06 & 0.26 \\
\hline 2 & Plain Concrete & 0.06 & 0.26 \\
\hline 4 & Reinforcement (Fe 500) & 16.00 & 43.00 \\
\hline 5 & Concrete Block Masonry & 0.05 & 0.22 \\
\hline 6 & Gypsum Plaster & 0.07 & 0.26 \\
\hline 7 & Sand plaster & 0.07 & 0.26 \\
\hline 10 & Hard wood Door & 2.27 & 6.93 \\
\hline 11 & Steel Doors & 24.00 & 64.50 \\
\hline 12 & Aluminium Windows & 28.56 & 86.10 \\
\hline 13 & Ceramic tiling & 22.60 & 64.56 \\
\hline 14 & Granite Tiling & 3.74 & 11.21 \\
\hline 15 & Natural Slate stone & 6.46 & 21.52 \\
\hline 16 & Cement tiling & 0.38 & 4.73 \\
\hline 17 & Steel Works & 24.00 & 64.50 \\
\hline 19 & Formwork Conventional & 61.11 & 215.27 \\
\hline 20 & Formwork special & 41.65 & 148.61 \\
\hline 21 & Membrane Water proofing & 0.11 & 0.52 \\
\hline
\end{tabular}

\subsection{SUSTAINABILITY DEVELOPMENT INDEX (SDI) MODEL}

Sustainability Development Index (SDI) proposed in this discussion is a dimensionless synergic factor. It is the algebraic sum of I1, I2 and I3. Figure 4 shows Sustainability Development Index (SDI) model that is applicable to buildings and infrastructure projects, prescribing the process of evaluation.

\subsection{APPLICATION OF SDI MODEL TO FORMWORK SYSTEM (CASE STUDY)}

As a case study SDI was calculated to assess the impact of various components of three different formwork systems on environment. Formwork is one of the most neglected areas in the Life cycle of a high-rise building and there is no detailed comparative energy impact assessment data that is available. The building considered for assessment was a multistoried residential building in Bangalore, India. The structure with total super built-up area of $73600 \mathrm{sqm}$ is with three Basements + Ground Floor + 27 symmetric upper floors. Total Formwork area is 165000 sqm. Structure constructed is a regular rigid concrete frame with light weight blocks for internal walls and exterior envelope. Formwork used is conventional type with adjustable props, U-heads, Steel floor plates as sheathing, Timber for stingers, joists and other supports, Plywood for beams. The joints between floor plates were closed using standard shutter tapes to avoid slurry leak. Impact comparison was made between three systems of formwork namely, sheathing with steel floor plates, sheathing with plywood for fair face concrete and sheathing with larger Aluminium floor plates.

Applying the process described in Figure 4, EE, EC and combined interaction values are calculated per Square meter of constructed area and presented in Table 3. From Table 3, it is seen that Formwork with Aluminium System provides least energy impact. Though the capital cost of Aluminium Formwork per Sqm is very high, the system overrides all other systems mainly due to recyclability and number of repetitions it offers.

Table 3: EE, EC, Interaction Indices Comparison

\begin{tabular}{|l|c|c|c|c|}
\hline \multicolumn{1}{|c|}{ FO RMWORK SYSTEM } & $\begin{array}{c}\text { EE/SQM } \\
\text { MJ }\end{array}$ & $\begin{array}{c}\text { EC/SQM } \\
\text { Kg CO2e }\end{array}$ & $\begin{array}{c}(\mathrm{I} 1+\mathrm{I2}+\mathrm{I3}) \\
\text { /SQM }\end{array}$ & REMARKS \\
\hline $\begin{array}{l}\text { CONVENTIONAL FORMWORK } \\
\text { WITH TIMBER JOISTS, STEEL } \\
\text { SPANS AND PROPS, STEEL } \\
\text { FLOOR PLATES }\end{array}$ & 229 & 18.43 & 90254 & \\
\hline $\begin{array}{l}\text { AS ABOVE BUT USING RESIN } \\
\text { COATED PLYWOOD FOR } \\
\text { SHEATHING }\end{array}$ & 234 & 18.81 & 31781 & \\
\hline $\begin{array}{l}\text { AS ABOVE BUT SHEATHING WITH } \\
\text { ALUMINIUM FLOOR PLATES }\end{array}$ & 15.6 & 2.5 & 30490 & $\begin{array}{c}\text { LEAST } \\
\text { IMPACT }\end{array}$ \\
\hline
\end{tabular}




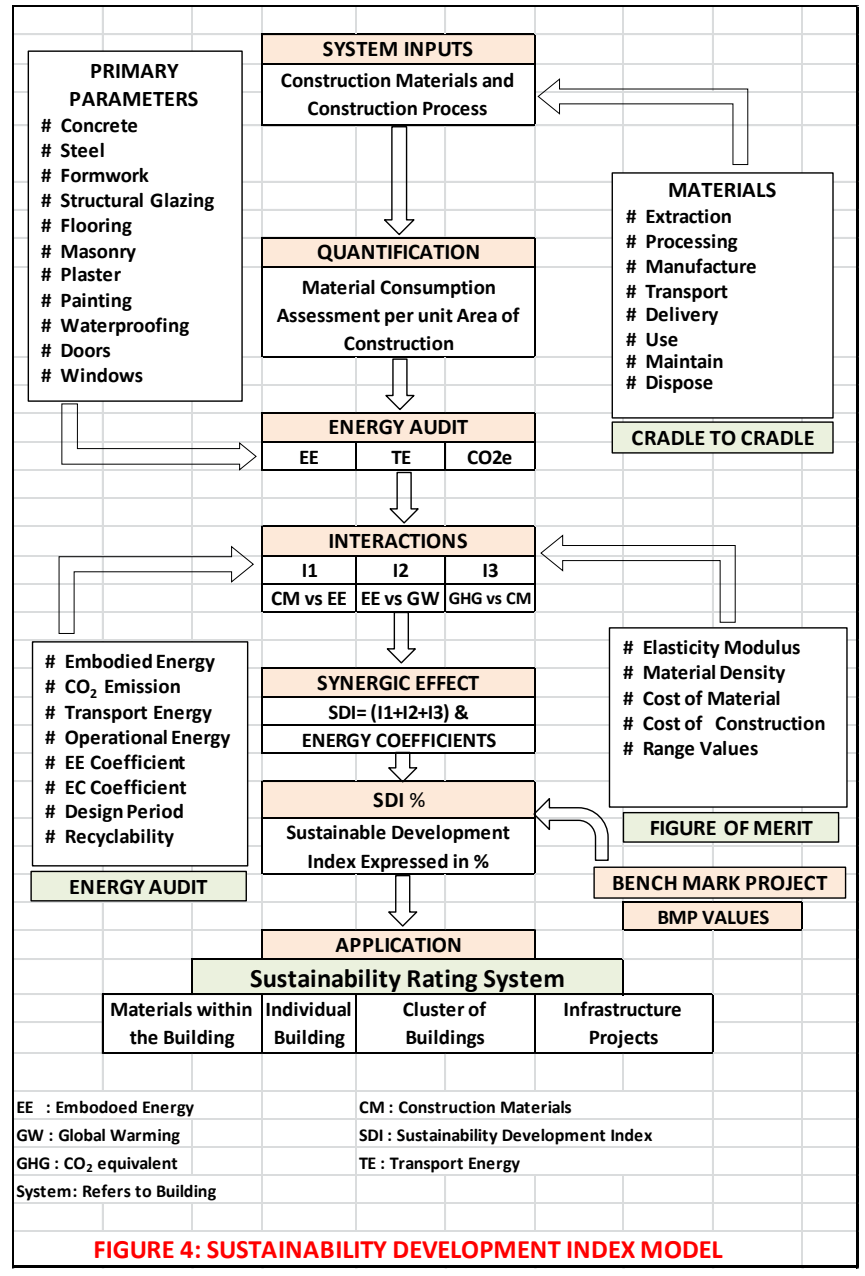

Figure 4: Sustainability Development Index Model

\subsection{DISCUSSION}

The interaction phenomenon that exists between Construction Materials (CM), Embodied Energy (EE) and Global Warming $\left(\mathrm{CO}_{2} \mathrm{e}\right)$ has been highlighted. The interaction between any two subsystems like CM-EE (I1) or EE-GW (I2) or CM-GW (I3) give rise to a unique Sustainability Development Index (SDI). The synergic factor due to three subsystems of interaction will be higher than the algebraic summation of earlier mentioned interaction factors. However, algebraic summation will be the lowest value of SDI and hence used in the present investigation. SDI can be assessed prior to the commencement of construction as properties of materials and other supporting systems of construction and transportation are finalized before placing the work order for construction. Hence, FoM can be determined and I1, I2 and I3 evaluated. Based on SDI, the modifications either in type of materials or methodology or transportation can be suitably modified to attain a better SDI. Hence, FoM can be considered as a tool for development of SDI.

The parameterization done at various subsystems will yield large number of combinations for material selection. Concept of determining the Sustainability Development Index (SDI) using the concept of Figure of merit is introduced in this paper.

\subsection{CONCLUSION}

It is now an established fact that Embodied energy, Embodied Carbon, Transport energy, Greenhouse gasses emitted and interaction between these subsystems are all intricately connected. Higher the EE, higher will be the EC and higher will be the impact on Global warming. Concept of assessment of construction materials in sustainable design is evolved as discussed above.

Development of Sustainable Development Index (SDI) is a preventive approach rather than curative approach.

\section{ACKNOWLEDGEMENTS}

The authors express their gratification to the authorities of Jain University for extending facilities in preparation of this paper and also for the encouragement to carry out the research.

\section{REFERENCES}

[1] Adrian Smith, Design Intelligence Publications, 'Tall, Global and Sustainable', September 18th, 2013.

[2] Will Pank, Herbert Girardet, Greg Cox, Report on 'Tall Buildings and Sustainability', Greater London Authority (GLA) in 2002.

[3] Knoke ME, Managing Editor, CPP. High-rise structures: life safety and security considerations. In: Protection of Assets Manual. Alexandria, VA: ASIS International; 2006.

[4] Jukka Heinonen, Antti Saynajoki, Juha-Matti Junnonen, Amalia Poyry, Seppo Junnila, Pre-use phase LCA of a multi-story residential building: Can greenhouse gas emissions be used as a more general environmental performance indicator?; Building and Environment 95 (2016) 116-125

[5] Saynajoki, J. Heinonen, S. Junnila, A scenario analysis of the life cycle greenhouse gas emissions of a new residential area, Environ. Res. Lett. 7 (3) (2012).

[6] Jingke Hong, Geoffrey Qiping Shen, Yong Feng, William Sin-tong Lau, Chao Mao, Greenhouse gas emissions during the construction phase of a building: a case study in China, Journal of Cleaner Production 103 (2015) 249-259

[7] Ignacio Zabalza Bribián, Antonio Valero Capilla, Alfonso Aranda Usón, Life cycle assessment of building materials: Comparative analysis of energy and environmental impacts and evaluation of the ecoefficiency improvement potential; Building and Environment 46 (2011) 1133-1140

[8] Manish K. Dixit, Jose L. Fernández-Solís, Sarel Lavy, Charles H. Culp ; Need for an embodied energy measurement protocol for buildings: A review paper; Renewable and Sustainable Energy Reviews 16 (2012) 3730- 3743

[9] Paolo Foraboschi, Mattia Mercanzin, Dario Trabucco; Sustainable structural design of tall buildings based on embodied energy; 2014, Energy and Buuildings,254269 
[10] Manish Kumar Dixit *, José L. Fernández-Solís, Sarel Lavy, Charles H. Culp, Identification of parameters for embodied energy measurement: A literature review; Energy and Buildings 42 (2010) 1238-1247

[11] G. Hammond. Jones, Inventory of Carbon and Energy (ICE), Version 1.5a Beta, Carbon Vision Buildings Program, University of Bath, UK, 2006

[12] J.A. Alcorn, G. Baird, Use of a Hybrid Energy Analysis Method for Evaluating the Embodied Energy of Building Materials, Center for Building Performance and Research, Victoria University of Wellington, New Zealand, 1996.

[13] A.H. Buchanan, B.G. Honey, Energy and carbon dioxide implications of building construction, Energy and Buildings 20 (3) (1994) 205-217.

[14] K. Adalberth, Energy use during the life cycle of buildings: a method, Building and Environment 32 (4) (1996) 317-320.

[15] K. Adalberth, Energy use during the life cycle of single-unit dwellings: examples, Building and Environment 32 (4) (1996) 321-329.

[16] S. Pullen, Energy used in the construction and operation of houses, Architectural Science Review 43 (2) (2000) 87-94.

[17] R.H. Crawford, G.J. Treloar, An assessment of the energy and water embodied in commercial building Construction, in: 4th Australian LCA Conference, Sydney, Australia, 2005.

[18] M. Lenzen, C. Dey, B. Foran, Analysis, energy requirements of Sydney households, Ecological Economics 49 (3) (2004) 375-399

[19] B.V. Venkatarama Reddy, K.S. Jagadish, Embodied energy of common and alternative building materials and technologies; Energy and Buildings 35 (2003) 129-137.

[20] Michael f Ashby, Materials and the Environment, Book,BH Publications, 2009

[21] Adrián Barrera-Roldán, Américo Sald'1var-Valdés, Proposal and application of a Sustainable Development Index, Ecological Indicators 2 (2002) 251-256

[22] Binh K. Nguyen and Hasim Altan, Tall-Building Projects Sustainability Indicator (TPSI): A New Design and Environmental Assessment Tool for Tall Buildings, Buildings 2012, 2, 43-62; doi:10.3390/buildings2020043

[23] G.A. Blengini, T. Di Carlo, Energy-saving policies and low-energy residential buildings: an LCA case study to support decision makers in Piedmont (Italy), Int. J. Life Cycle Assess.15 (2010) 652e665.

\section{BIBLIOGRAPHY}

[24] Embodied Energy and its impact on Architectural Decisions-by H.J. Holtzhausen, Faculty of Art, Design and Architecture. University of Johannesburg, EcoArchitecture conference 14-16 June 2006

[25] Energy Briefing Sheet: Embodied Energy and CarbonICE, Proceedings of the ICE - Energy, 164, 195-204 ... (2010.1), updated 2015

[26] Construction materials And The Environment-Arpad Horvath, Department of Civil and Environmental
Engineering, University of California, Berkeley, California 94720; 2004

[27] Materials for Sustainable Sites-Meg Calkins, Published by John Wiley \& Sons, Inc., Hoboken, New Jersey, 2009,

[28] Low Energy Green Materials by Embodied Energy Analysis Rohit Deshmukh, Ashok More; International Journal of Civil and Structural Engineering Research ISSN 2348-7607 (Online) Vol. 2, Issue 1, pp: (58-65), Month: April 2014 - September 2014,

[29] Hammond, G. P. and Jones, C. I. (2008) Embodied energy and carbon in construction materials. Proceedings of the Institution of Civil Engineers - Energy, 161 (2), pp. 87-98. ISSN 1751-4223; 2008

[30] Embodied energy considerations for existing buildingsHistoric Scotland Technical Paper 13, Gillian F. Menzies; 2011

[31] Inventory of Carbon and Energy (ICE); Prof. Geoff Hammond and Craig jones, Sustainable Energy Research Team (SERT), Department of Mechanical Engineering, University of Bath, UK. 2011

[32] Buildings and Climate Change- United Nations Environment program for Sustainable Buildings and climate Change; Publication under Sustainable Buildings and Climate initiative, 2009

[33] Ajit Sabnis, Pranesh Mysore, Shashi Anant; Construction Materials, Embodoed Energy Footprint, Global Warming Interaction; International Conference presentation; $5^{\text {th }}$ Structural Engineering World Congress, Singapore, October, 2015

\section{BIOGRAPHIES}

1. Ajit Sabnis, Department of Civil Engineering, School of Engineering and Technology, Jain University, Bangalore, India (ajit.sabnis@jainuniversity.ac.in)

2. Pranesh Mysore, Prof., Department of Civil Engineering, School of Engineering and Technology, Jain University, Bangalore, India (mrpewit@gmail.com) 